\title{
Correction to: A Review of Current Denervation Techniques for Chronic Hip Pain: Anatomical and Technical Considerations
}

\section{Pranab Kumar $^{1}$ - Yasmine Hoydonckx ${ }^{1}$. Anuj Bhatia ${ }^{2,3}$}

Published online: 28 May 2019

(C) Springer Science+Business Media, LLC, part of Springer Nature 2019

Correction to: Current Pain and Headache Reports (2019)

23: 38

https://doi.org/10.1007/s11916-019-0775-z

In the original publication, the legend in the Figure 1 caption were missing and Table 2 was not presented correctly.

The original article has been corrected.

Publisher's Note Springer Nature remains neutral with regard to jurisdictional claims in published maps and institutional affiliations.

The online version of the original article can be found at https://doi.org/ 10.1007/s11916-019-0775-z

Anuj Bhatia

anuj.bhatia@uhn.ca

Pranab Kumar

pranab.kumar@mail.utoronto.ca

Yasmine Hoydonckx

yasminehoydonckx@gmail.com

1 Department of Anesthesia and Pain Management, University Health Network-Toronto Western Hospital, University of Toronto, Toronto, Canada

2 Department of Anesthesia and Pain Management, University Health Network-Toronto Western Hospital and Women's College Hospital, University of Toronto, Toronto, Canada

3 Institute of Health Policy Management and Evaluation, Toronto, ON, Canada 